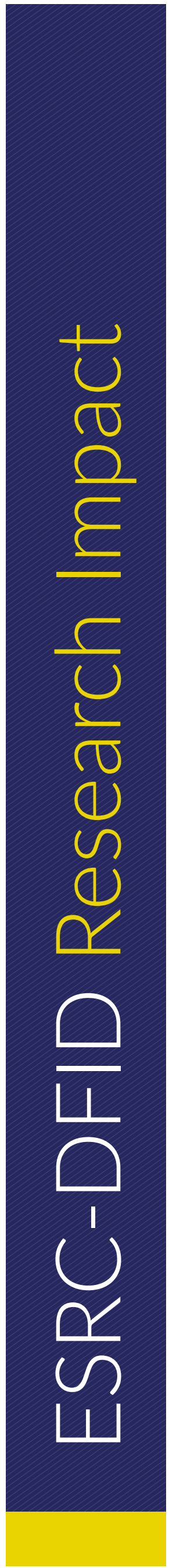

\title{
REDUCING SCHOOL DROPOUT RATES IN MALAWI AND LESOTHO
}

'School in a bag', buddy systems and catch-up clubs have paved the way for improved learning and reduced dropout in schools in Malawi and Lesotho. These pioneering techniques have been used by researchers from University College London's Institute of Education and their Southern African partners to help ensure that disadvantaged children, particularly those affected by HIV/ AIDS, stay in school.

\section{Between April 2007 and July 2010, the team} developed and piloted these distance- and flexiblelearning techniques in 20 primary schools in Malawi and 16 secondary schools in Lesotho, all of which were located in areas where HIV/AIDS was highly prevalent and where school dropout rates were high. In both countries, the schools saw reduced dropout rates (up to 45 per cent in Malawi), particularly for older children.

\section{THE CHALLENGE}

Many developing countries have made good progress in improving enrolment rates since universal primary education became a UN global target over 15 years ago. But for countries in Africa such as Lesotho and Malawi which are deeply affected by the HIV/AIDS crisis, these gains mask a troubling picture of low levels of achievement and worrisome dropout rates. For orphaned or vulnerable children who struggle to attend class, for example because they care for chronically ill parents or work to support themselves and their families' income, the problem is made worse by school policies which actively discriminate against poor households.

\section{THE RESEARCH}

The research team wanted to study whether a flexible approach to learning could improve educational achievement and reduce the risk of dropout for vulnerable children. Key components of their groundbreaking SOFIE model included a 'school in a bag that held pens, notebooks, textbooks and self-study

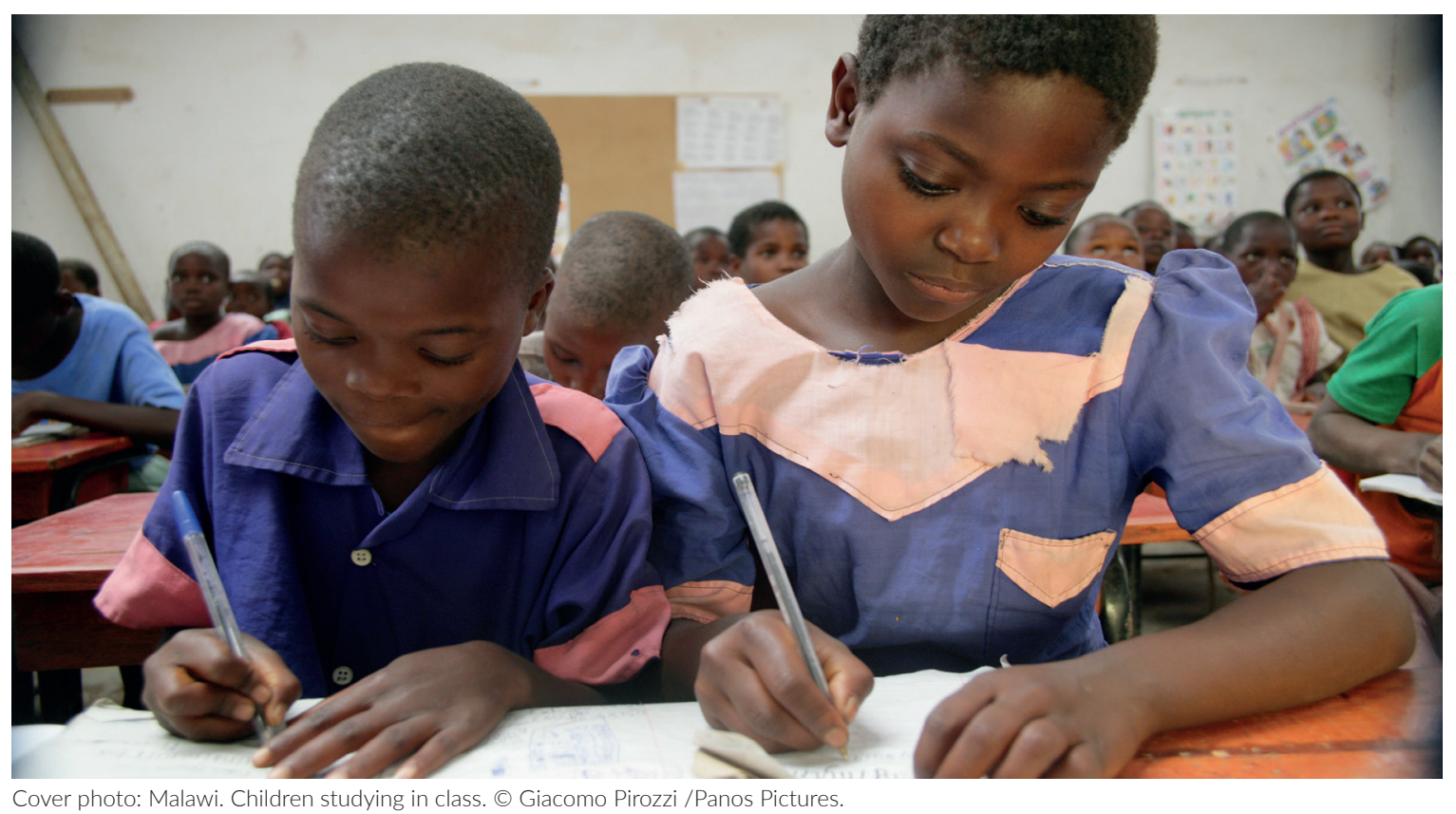

1. The South African Institute for Distance Education (SAIDE); the Institute of Education, National University of Lesotho; and the Centre for Education Research and Training (CERT), University of Malawi.

2. Strengthening Open and Flexible Learning for Increased Educational Access in High HIV Prevalence Countries. 
guides for English and Maths designed to encourage independent learning for children for whom school attendance was often erratic; a buddy system providing peer-support for learning; and catch-up clubs run by youth volunteers providing additional learning opportunities in friendly, informal environments, and which were arranged after school hours.

\section{THE IMPACT}

In both countries, school dropout rates reduced and Maths scores improved. In fact, the positive effects spilled over to a much wider group thanks to improved teacher engagement and changes in exclusionary practices. Children's confidence and self-esteem increased, and the buddy system helped reduce isolation and discrimination, build friendships, and increase motivation to continue with school.

Particular success was attributed to the innovative selfstudy guides and, critically, the collaborative nature of the project - community members, teachers and youth volunteers were all included in helping to improve the inclusiveness of schools by developing 'circles of support' around vulnerable children at risk of dropping out of school.

\section{W}

Against a context of underlying poverty and disadvantage, having someone who provides emotional support, takes an interest and pays attention to whether they are in school or not, be it a buddy, teacher, community leader, is of great value to pupils who regularly experience isolation.

Malawi lead researcher Catherine Jere

Findings from the project have played an important role in demonstrating how conventional schooling can be adapted for children struggling to attend and remain in education.

In Lesotho, the CEO for Curriculum Assessment has used the findings to raise the profile of open and flexible learning techniques within the Ministry of Education; and a formal qualification for teachers on guidance and counselling has been initiated.

In Malawi, pilot schools put in place plans to change discriminatory school policy, improve their inclusiveness, and support disadvantaged children.
The project also reinforced the Ministry of Education's ongoing re-assessment of the country's distance education strategies. Templates of the self-study guides were shared with district education offices and project outcomes informed the design of nongovernmental 'bridging' programmes and clubs to provide learning support for senior primary girls during the transition to secondary education and to reduce the risk of dropout. Several of the youth volunteers involved in the project have since been accepted onto a national distance-learning teacher training programme.

\section{FURTHER READING}

Jukes, M.C.; Jere, C.M. and Pridmore, P. (2014) 'Evaluating the Provision of Flexible Learning for Children at Risk of Primary School Dropout in Malawi', International Journal of Educational Development 39: 181-92

Jere, C.M. (2012) 'Improving Educational Access of Vulnerable Children in High HIV Prevalence Communities of Malawi: The Potential of Open and Flexible Learning Strategies', International Journal of Educational Development 32.6: 756-63

Pridmore, P. and Jere, C.M. (2011) 'Disrupting Patterns of Educational Inequality and Disadvantage in Malawi', Compare: A Journal of Comparative and International Education 41.4: 513-31

Pridmore, P. (2010) End of Award Report: Strengthening ODFL Systems to Increase Education Access and Attainment for Young People in High HIV Prevalence SADC Countries, Swindon: ESRD

http://sofie.ioe.ac.uk/

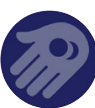

Strengthening ODFL systems to increase education access and attainment for young people in high HIV prevalence SADC countries

The research team was funded by ESRC-DFID's Joint Fund for Poverty Alleviation Research, led by Principal Investigator Professor Pat Pridmore and Chris Yates, University College London's Institute of Education, team statistician Matthew Jukes, Harvard University, Ephraim Mhlanga, South African Institute for Distance Education and in collaboration with the incountry researchers Catherine Jere, the University of Malawi and the National University of Lesotho.

\section{THE IMPACT INITIATIVE}

\section{For International Development Research}

\footnotetext{
The Impact Initiative seeks to connect policymakers and practitioners with the world-class social science research supported by the ESRC-DFID Strategic Partnership, maximising the uptake and impact of research from: (i) the Joint Fund for Poverty Alleviation Research, and (ii) the Raising Learning Outcomes in Education Systems Programme. We seek to identify synergies between these programmes and their grant holders, support them to exploit influencing and engagement opportunities, and facilitate mutual learning. The Impact Initiative is a collaboration between the Institute of Development Studies (IDS) and the University of Cambridge's Research for Equitable Access and Learning (REAL) Centre.
}

\section{CREDITS}

This impact story was written by Elizabeth Tofaris, Faculty of Education, University of Cambridge, in collaboration with Catherine Jere, now with the University of East Anglia.

info@theimpactinitiative.net www.theimpactinitiative.net @the_Impact_Init \#impactlessons

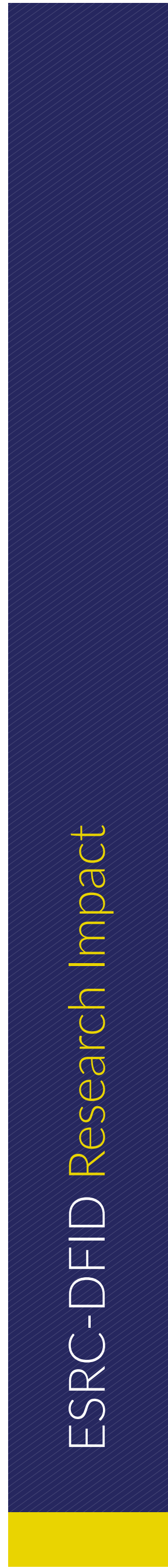

